\title{
Apuntes prosaicos para una gimnástica ciudadana
}

Prosaic notes for a civil gymnastics

\author{
William Moreno Gómez
}

Cabe entonces preguntarnos, cómo hemos de devolver los cuerpos a los espacios y paisajes de la ciudad. $O$, lo que es lo mismo: cómo hemos de recuperar la ciudad para los cuerpos. Claudia Zavaleta

\section{Resumen}

\begin{abstract}
En este artículo abordaré lo que denomino tres afanes para no perder la pista de la educación corporal en la ciudad. La emergencia de un campo para la educación corporal, la des-sublimación de una práctica corporal y la desescolarización, la escuela para el cuerpo configuran tres hilos de una misma trama (la educación corporal) que permiten visualizar un punto de vista sobre asuntos cruciales para la conformación de un espacio para las educaciones del cuerpo en el contexto de una ciudad que se sueña educada y educadora antes que soñarse escuela o ciudad escolarizada.
\end{abstract}

Palabras clave: Ciudad, cuerpo, educación corporal, práctica corporal, desescolarización, Educación Física.

\section{Abstract}

The present text approaches what I call three efforts not to lose track of corporal education in the city. The emergence of a field for corporal education, the des-sublimation of corporal practice and deschooling, and the body school are three threads of the same fabric (corporal education) providing a point of view on crucial matters for the building of a space for body educations in the context of a city that sees itself as educated and educational rather than as schooling or deschooling.

Key words: $\quad$ City, body, corporal education, corporal practice, deschooling, Physical education.

Fecha de recepción: 28 de septiembre de 2007

Fecha de aceptación: 26 de octubre de 2007

* Licenciado en Educación Física de la Universidad de Antioquia. Doctorado en Educación de la Universidad de Valencia. Autor de Cuerpo, escolarización e intervención pedagógica. 


\section{Sobre la emergencia de un campo para la educación corporal}

Nos asignaron un tiempo del cuerpo para que desde un espacio reglado (pedagógico), acogiéndolo, lo conformáramos. La representación, la idea, las creencias ${ }^{1}$, las teorías implícitas, las concepciones, las metáforas, los constructos ${ }^{2}$ y las prácticas sobre tal encargo y para éste, en correspondencia con la perspectiva que se asuma, se han ido simplificando o complejizando.

Desde la primera perspectiva, producto de la recontextualización prescriptiva (Díaz, 2001) y del proceso de la alienación ${ }^{3}$ técnico-racional (Schön, 1992) de la educación física a campos explicativos hegemónicos ${ }^{4}$, podría leerse una deflación de la educación corporal -específicamente de la educación física, a una especie de apéndice- que se habría ido limitando de modo paulatino a una región aplicativa pedagógica ${ }^{5}$ con dependencia intelectual-explicativa de otros campos $y$ regiones de la ciencia (socio, bio, psi, etc.). Subsumida por la lógica de la secuencia hegemónica: ciencias básicas-ciencias aplicadas-técnicas de práctica (López Ruiz, 1999: 73), aparece hoy como un campo recontextualizado y dependiente. Técnica práctica ${ }^{6}$ centrada en la con-formación de un modo de ser, presentar, accio-

1 Verdades personales o grupales derivadas de la experiencia o la fantasía (Ponte, 1992, en Gil Cuadra, 2002). Elliot vincula el análisis de las creencias en la influencia mutua entre pensamiento y práctica profesoral.

2 Carr y Kemis (1988) plantean al respecto que "la ciencia social crítica intenta localizar en sus ideas los equívocos colectivos de los grupos sociales". Se puede aventurar que en la base de las creencias orientantadoras de nuestra práctica están acrisolados un sinnúmero de equívocos, que pueden ser localizados por los propios actores para su posible superación.

3 Referencio el concepto de educación física alienada usado por Crisorio (2002: 27-34). Consultando la llamada identidad disciplinar se plantea que tanto el pasaje de la paidotribia a la gimnástica en Grecia, como el cambio de la gimnástica por la educación física "científica" desde finales del siglo XIX (en Europa y desde otro continente), identifican procesos de alineación de la educación física a presupuestos extraños. Referencia el discurso de las ciencias de la actividad física y el deporte, el discurso de una ciencia del movimiento humano, de la praxiología motriz y de la motricidad humana como espacios del saber que constituyen alienaciones de la educación física al discurso de la ciencia moderna. La subsidiareidad del campo y el poder de los "prescriptores científicos" quedan abiertos desde tales discursos. Desde una perspectiva colonial, se considera que poseemos técnica, no saber.

4 Schön habla de lastres heredados de la racionalidad técnica conectados con la lógica de la secuencia hegemónica: ciencias básicas-ciencias aplicadas-técnicas de práctica (López Ruiz, 1999: 73).

5 Es lo que Martínez Âlvarez (2000: 86) denomina como saber complementario (residual).

6 Williams (1989), citado por Martínez Álvarez (2000) plantea que los orígenes de la educación física en el currículo escolar son más utilitarios que educativos. Foucault (1994: 101), con relación a la intervención corporal, diferencia las prácticas que buscan modificar el modo de ser de las que solo aspiran a dotarlo de capacidad. nar y competir (a la manera de la "competencia educactiva") con el cuerpo.

Desde la segunda perspectiva, problémica y crítica, entendiendo la educación física como práctica y como saber (perspectiva minoritaria), emerge un campo de saber que quiere configurarse allende los dogmas y doctrinas que han querido imponer un tutelaje a las educaciones corporales, se dibuja una complejidad que se cultiva por la pregunta, por la confrontación, y por los intentos de proyección, a partir de la concentración en el campo de intervención social asignado o apropiado para el despliegue de las prácticas corporales que apuntan a la formación (complejidad en función del proceso contrario a la alienación).

La primera se ve favorecida por la desvalorización social del área en la escuela, la informalización económica y profesional del campo como lugar de desempeño de un trabajador pauperizado, y por la reafirmación hegemónica de las explicaciones somatognósicas, tecnocráticas y empresaristas (para la Organización Mundial de Comercio, OMC, la educación es un bien por adquirir, una mercadería) de la vida cotidiana animadas por las prescripciones biotecnologizadas.

La segunda perspectiva se va dibujando alimentada por la ampliación del encargo (ya no reducido sólo al marco escolar), la ampliación de sus demandas explicativas y reproductivas (que desborda los marcos disciplinares explicativos tutelares tradicionales de la educación física ${ }^{7}$ ), y por los esfuerzos reflexivos crecientes de una comunidad académica específica que intenta consolidarse a punta de consultar el quién soy (interrogante exploratorio ${ }^{8}$ que aún prevalece) y a los interrogantes confrontativos de a qué y a quién me debo (interrogantes aún incipientes).

Este debate se va desarrollando en medio de difíciles condiciones de posibilidad. Prevalece una especie de tabú y representación histórica de desprecio (a ultranza) por la educación física, sobre todo por la legación social del campo. Como veremos más adelante, esta actitud se

\footnotetext{
Bracht (2002), en Crisorio (2002), reconoce una tensión deconstructiva de los conceptos fundantes de la educación física (construidos en consonancia con el universo simbólico de la modernidad) por parte de las representaciones provenientes de un universo simbólico de corte posmoderno centrado en referentes plurales y antifundacionalistas, relacionados con la duda y la incertidumbre.

8 Se evidencia en esta comunidad académica una preocupación histórica por tener estatuto (estatus) en el marco de la ciencia moderna (tener carácter científico); afán por dilucidar la originalidad y los diferenciadores de distinción disciplinar, entregados a definir apriorísticamente el objeto y, desde allí, un subsecuente programa disciplinar. Crisorio (2002: 22) plantea que la eterna pregunta por el objeto de estudio es un reflejo de una preocupación permanente y distractora de nuestra comunidad académica por la identidad.
} 
extiende a una deuda social de calado histórico por la dignidad política, profesional, intelectual y estética de quienes encarnamos el poder-saber de las educaciones corporales de las gentes de la ciudad en sus distintos escenarios de despliegue social (escolar, recreacional, militar, artístico, higiénico, jurídico, penal, habitacional, callejero, medial y deportivo ${ }^{9}$ ).

La revisión es demandante. El tratamiento del cuerpo en la escuela no escapa a las leyes de una "escuela científica", entendido lo científico en el ribete epistémico que impone el paradigma hegemónico de ciencia. Decía Calvo (1994) que "es tan profunda la aprensión por la cientificidad de la labor escolar que se pasa por alto que no es posible que un fenómeno y proceso educativo no forme parte del sistema total de la cultura, por caótico, casual y fortuito que sea". Para este pedagogo chileno, des-escolarizar la escuela significa recuperar la potencialidad sinérgica de los procesos educativos; allí el lugar para el cuerpo es otro. Para esta perspectiva pedagógica y estética, la educación es otra cosa; es eutópica, no obliga al logro unívoco de determinadas metas; reconoce el valor del deber ser (axiología educativa), pero no lo exige en el terreno de las realizaciones contingentes. Según él, de este modo, el campo de la educación es el de lo posible, del poder ser, de lo posible y de lo probable, tiene que ver con la diversidad y la heterogeneidad, antes que con la unidad y la homogeneidad. Lamentablemente, subraya, la escuela, engañada por la ilusión de la unidad atribuye des-orden a la diversidad y prefiere canalizar sus esfuerzos escolares por el camino de la repetición (Calvo, 1994: 2). Esta atribución cobra mayor visibilidad en las prácticas corporales tradicionalmente circunscritas en el campo de la educación física, cívica, artística e higiénica escolar. El hecho de que la escuela funde el valor de los procesos educativos de enseñanza-

70 aprendizaje en la causalidad representa ya una limitación epistemológica grave, porque, como plantea Calvo (1994: 7), se excluyen las relaciones sincrónicas, sinérgicas y holísticas del proceso educativo. Considera Taborda (2002: 143) que la escuela se queda corta; desde su perspectiva, debería trascender los contenidos formales que, reducidos a lo que denomina una "cultura corporal de movimiento", no alcanza a proyectar la formación humana que predica.

La educación física y todas aquellas prácticas escolares estéticas como las prácticas artísticas, higiénicas,

\footnotetext{
9 La búsqueda de la procedencia no funda (y no es para fundar o refundar), sino que, según Foucault (1980: 13), remueve aquello que se percibía inmóvil; fragmenta lo que se pensaba unido; muestra la heterogeneidad de lo que se imaginaba conforme a sí mismo.
}

disciplinantes, etc. ( Milstein y Méndez, 1999) se juegan en la otra banda (ya ubicada por Adorno, 1974: 74) de la escuela; hay allí una doble jerarquía que permanece latente, una oficial (según capacidad y demanda intelectual) y otra no oficial, subsidiaria, tímida, ocultada, vergonzante en la que juega su papel la fuerza física, el vigor, la salud, el temple, la feminidad y la masculinidad, la competitividad, el héroe, el campeón. En esta última lo que prima es: ser un hombre o ... ser una buena dama (feminización)... un macho (masculinización), un ejemplar de la tierra propia (folclorización), un campeón imperturbable (heroización)... un defensor incondicional del estatu quo, etc. Los nacionalismos de diverso cuño, recordaba el pensador alemán, se han apoyado en estas bondades corporales que ha cultivado la escuela a través de las prácticas de con-formación corporal (dispositivos de intervención pedagógica de lo corporal). En el discurso moderno y posmoderno se proponen y legitiman prácticas corporales y teorías formales sobre la superioridad racial, de clase, de género, de capacidad o habilidad, de edad, de generación, de conocimiento o nacionalidad que, según Gimeno (2003: 77), no son "supersticiones arrastradas de los tiempos negros", sino estereotipos que funcionan en las prácticas con el cuerpo que nosotros mismos facilitamos. En nuestras escuelas tensas en medio del conflicto no es raro escuchar el reclamo, no solo desde las altas esferas, sino desde nosotros mismos, de la presencia de profesores hombres, de edufisicos con calzones, de prácticas físicas exigentes, sacaleches, de "educaciones para negros", de exclusión de los especiales o de los raros, de selecciones y enmarcaciones corporales excluyentes en el medio escolar y en el medio educativo de ciudad, lo cual está relacionado con estereotipos que han pasado camuflados, agachados y retocados por los cedazos humanistas y flexibilizadores de la escuela. Hay que hacer eco; la escuela encasilladora de cuerpos puede ser para el individuo un eslabón significativo de la cadena de la alienación social.

Lo que hacemos a través de las prácticas corporales debería ser pensado en función de la educación y la formación, en contravía de la con-formación corporal a la que nos arrastra la energía de la "educación científica". Ello nos obliga a revisar el entusiasmo y la fe recontextualizadora que hemos puesto en la autoridad, las razones y los encargos que nos han sido asignados históricamente, por no decir impuesto o heredado, desde las propias ciencias y disciplinas instituidas. Cobran sentido las sugerencias de Calvo (1994: 2) y Crisorio (2002: 24); superando la fuerza de la doctrina y el dogma, la posibilidad de dirigir la mirada y la capacidad configu- 
rativa de hacer, saber y conocer pedagógico corporal hacia estas educaciones corporales, con independencia del lugar que pueda o no corresponderle en el campo escolar (formal, informal, no formal) o científico. Puede ser una opción para presentar, desde estas prácticas con el cuerpo, otras posibilidades a la gente de la ciudad. Si se quiere, pensando que en las márgenes y los extramuros de esos "saberes cultos y científicos", y en las márgenes y extramuros de la educación formal, en lugares despreciados como los saberes del sentido común, los saberes prácticos corporales de las propias comunidades y prácticos profesionales del profesorado, hay espacios para una reconfiguración posible del campo de la pedagogía corporal. Formas posibles de educaciones corporales no subsidiarias.

Apremia el enganche histórico con los procesos de desfiguración, configuración y reconfiguración del campo de saber de la educación física (real y simbólico pedagógico) contextualizado (historia, sociedad y cultura). A pesar de nosotros, ya existe participación como comunidad académica en los ámbitos de configuración epistémicos (nodos y referentes conceptuales y metodológicos), el decantamiento de una cultura propia ${ }^{10}$ de la formación corporal y de una cultura académica de los procesos de habilitación profesional e investigación corporal situada en posibles referentes para una intervención corporal de nuevo cuño.

\section{La des-sublimación de una práctica corporal}

A fuerza de la colonización escolar de la vida, naturalizaron la escuela, hasta podemos creer que ella siempre ha estado allí; no nos damos cuenta que muchas de ellas están aún enclavadas en viejas casas familiares. En sí misma, a la manera pública y obligatoria, es un invento pautado por el poder del Estado de época muy reciente. En esta fábrica de sujetos (Varela y Álvarez Uría, 1991: 9), el poder pastoral y el poder civil han dejado una preformación que quiere un cuerpo acorde a lo social. Su andamiaje se constituye a partir de principios, criterios y estrategias de dominación mediadas por la autoridad,

${ }^{10}$ El conocimiento profesional es teórico y práctico. Shulman (1987), Bromme (1988), Porlan \& Martín (1994), dimensionan el saber profesoral como conjunto de elementos teóricos, serie de reglas, principios y pautas prácticas que tienen origen en la dilatada experiencia personal y social de los profesores, ver López Ruiz (1994: 74). Para Barbero y Hernández Martín (2000: 3) hay un convencimiento en los estudiantes de que saben (conocimiento social, deportivo, etc. previo), una formación paralela, Por ser deportista, entrenador, instructor, profesor iniciado o monitor, se estaría sumando al complejo del saber conseguido por vías "emergentes". la fuerza, la condición generacional, cultural o simplemente por la condición social y ciudadana subalterna de los escolarizados... "sean todos quietos, modestos y bien cristianos"11; "para despertar el deseo de fortificar la nación por el individuo el primer deber es hacer integral la formación educativa, cultivando físicamente al niño"12; "vienen a la escuela solo por el vaso de leche y el almuerzo"13; "si están acá se distraen y no están en la calle guerreando"14, así sea por razones moral-religiosas (catequesis) o de control y regulación higiénico-social (escuelas guarderías/nutricias) o política (escuelas barriales para la contención política o militar de la juventud). Estar en la escuela es ahora una necesidad académico proyectiva de orden laboral y político (de orden regulativo de conflicto), y de "desarrollo corporal básico" (alimentación, salud, higiene) que la hace más necesaria.

La escuela no es un artefacto que funciona como máquina simple, aunque lo parezca a ojos desprevenidos, sino que es compleja; en ella habita la contradicción; ha monopolizado y escolarizado los procesos educativos (Calvo, 1994: 1), pero en su interior, por presión desde fuera, funciona una cinética subrepticia, si se quiere subterránea (marginal, oculta) que, al decir de Calvo (1985), aunque lo pretenda, no puede controlar. Por una de las obras cumbres de Foucault, Vigilar y castigar (2002: 149), sabemos que en el logro escolar-institucional de un cuerpo bien disciplinado se forma el contexto operativo del menor gesto; el establecimiento de correlación cronémica y proxémica del cuerpo y del gesto es la base del control escolarizado y la base de un sistema más complejo de regulación social; ese es y será el plan de los acogimientos pautados (curricularizados) de los cuerpos. La intervención pedagógica de lo corporal impone "la mejor relación entre un gesto y la actitud global del cuerpo, que es su condición de eficacia y de rapidez... En el buen empleo del cuerpo, que permite un buen empleo del tiempo, nada debe permanecer ocioso o inútil: todo debe ser llamado a formar el soporte del acto requerido" (Ibíd.). Las habilidades y destrezas son productos escolares que demandan una gimnástica "cuyo

11 Regulaciones escolares del padre Nadal, citadas por Varela y Fernández (1991: 20).

12 Alberto de J. Duque profesor e intelectual colombiano de principios del siglo XX. En La escuela Nacional, 1918, Medellín, Tipografía Industrial.

13 De la entrevista a una profesora (por el estudiante Aldo Fernando González), trabajo de campo para su trabajo de Práctica en el semestre 2 de 2006. Instituto de Educación Física de la Universidad de Antioquia.

${ }^{14}$ Entrevista practicada por el autor a Guillermo Arango, coordinador de una institución educativa (febrero de 2005), sobre la distribución horaria escolar. En horario especial nocturno atienden un programa de educación para jóvenes desmovilizados. 
código riguroso domina el cuerpo por entero, desde la punta del pie a la yema del dedo índice" (Ibíd.).

El cuerpo escolarizado desplazándose entre los estados de santificación y patriotismo, buen estudiante y estado de parche ${ }^{15}$, folclorización y heroización, feminización y masculinización (por mencionar algunos de los dispositivos escolares que definen las condiciones para la producción y reproducción de la cultura corporal), discurre con mucha fuerza (dramática) en los mundos de la educación formal. Hay una distancia significativa en el uso social del tiempo y el espacio, entre la clase y el espacio tiempo del carnaval, entre el los aprendizajes posibles para el cuerpo bajo la tutela escolar y aquellos aleatorios e impredecibles allegados a través de la experiencia de la calle, de la esquina, del escarpado, de la cancha de barrio, de la vivencia cotidiana con escasa institucionalización.

Mucha contextualización y recontextualización ${ }^{16}$ ha pasado bajo el puente de la curricularización de la educación física para crear una distancia tan abismal entre divertimento y entrenamiento. Sugiere Soares (2006: 11) que a través de la constitución de una histórica censura y prohibición sobre aquellas prácticas divertidas (festivas, artísticas, inoficiosas, ociosas), que tenían al cuerpo como centro de divertimento y espectáculo, se crearon las condiciones que permitieron llegar a la domesticación tecno-científica de las prácticas corporales a la manera como hoy aparecen reunidas en la consigna con-formativa de la educación corporal escolarizada. Esta domesticación se deja ver en los vaciados didácticos de nuestros planes de clase o en el manual de educación física que se construye (generalmente) a nuestras expensas; también visible en las entrelíneas de los "democráticos" manuales de convivencia generalmente armados de la mano de "buenos y ejemplares estudiantes".

Las formaciones, las disposiciones escolares del cuerpo para la gimnástica escritural o para la gimnástica patriótica, la ejercitación higiénica, los ejercicios espi-

\footnotetext{
${ }^{15}$ El parche, en el lenguaje de los jóvenes de Medellín popular, es el lugar donde se reúnen los parces, los amigos, los propios, los de la gallada, los del combo. Da cuenta de un estado similar al "estado de boca esquina o de bocacalle ya identificado en sus investigaciones escolares por McLaren (1994).

16 Para Díaz (2001: 94), las prácticas pedagógicas (en este caso las corporales) implican un modo, una manera de ubicar a los alumnos en un orden legítimo y específico con respecto a normas legítimas, patrones o paradigmas de conducta, carácter y manera (intento por controlar la transformación de la experiencia corporal dentro de un sistema de relaciones sociales específicas). Recuerda que en términos de Bourdieu, la práctica escolar se relaciona con la producción de individuos equiparados con un sistema de patrones inconscientes que constituyen su cultura.
}

ritual-religiosos de cada mañana, de cada acto escolar, los rituales de "camaradería" previos a los encuentros deportivos, etc., se reúnen en paquetes de intervención pedagógica que se transmiten de generación en generación escolar. De los atletas de feria, de dios, de la patria y de la virtud se pasa al atleta adalid de la salud, del vigor, del deporte del espectáculo y de la representación; sólo que bajo estas consignas se ha tejido una particular y eficiente sujetación corporal. No importa el medio, entre educación deportiva y psicomotriz fluye en común la normalización física; finalmente, ellas apuntan a resultados de competencia; diría Crisorio (2002), a una salud sin sujeto. Para Soares (2006: 13), las prácticas corporales hablan, "atestiguan cambios profundos de costumbres, de relaciones de poder, de modos de vivir, pueden así mismo, ser comprendidas como una imagen más sensible de la interconexión entre naturaleza y cultura". En esas prácticas se puede aplicar una lectura de la cultura (ya escolarizada) operada sobre los cuerpos.

En la anotada línea de la complejización, se manifiesta una ambivalencia o un sentimiento encontrado. La institución educativa, la escuela, escudada en una retórica humanista y humanizadora, pero detenida en una práctica (ejercicio dramático) con-formativa tradicional, desde una especie de doble moral, atenaza los cuerpos. Se predica flexible y, a punta de reforma, a espaldas de los sujetos escolares sujetados, se reenmarca y reclasifica (acreditación social) con la idea de fortalecerse (de fortaleza) y hacerse, certera, productiva, competente, científica, deportiva y eficiente. En sus presupuestos se sigue mostrando como una de las instituciones con mayores niveles de reglamentación; desde una taylorización de nunca aflojar entre líneas presente, a pesar de tanto ladrillo y compu-técnica, se reafirma, con cambios retóricos que no alcanzan aún para modificar significativamente, de cara a la formación digna, la dramática ${ }^{17}$ de los cuerpos escolarizados. Para aquellos que propugnan levantar conciencia histórica de la escuela vivida en los últimos doscientos años ${ }^{18}$, es perceptible, desde la resignificación del currículo oculto, la preeminencia de una tecnología corporal regida por asomos significativos de la escolaridad del siglo XIX. Algunos de ellos ven, en

\footnotetext{
${ }^{17}$ Refiere a las condiciones de despliegue visibles en las demandas energéticas que la escuela y sus presupuestos imponen al cuerpo en la tarea que a fuerza de ejercitaciones intentan la conformación de un modo de ser, de exposición y de estar social. La ocupación del espacio y el tiempo social (Proxémica y cronémica) y la demanda motriz (pulso, densidad, cinética, intensidad, tono) marcan referentes que permiten penetrar la lógica de tal intervención pedagógica de lo corporal.

18 Véase estudios de García Gutiérrez y otros $(2000,2002)$ y los estudios pioneros de Saldarriaga y Sáenz (1997), Herrera y Buitrago (1999-2005) y Pedraza (2004), Zuluaga (1999a y 1999b).
} 
el lugar que ocupa el cuerpo en la escuela, una de las raíces de la crisis ${ }^{19}$ del pensamiento y las prácticas escolares corporales. Para el cuerpo, la escuela cambia de tecnologías, pero a la manera de vestiduras retocadas en las reformas sin memoria que se tejen prevalentemente desde fuera del marco de la escuela. La memoria pedagógica nunca ha convenido a las innovaciones bancarias de la escuela y la educación.

El cuerpo en la escuela está preso en los límites que le imponen los muros de las relaciones preestablecidas. Dice Calvo (1994: 1) que "hoy en día es un lugar común afirmar que la educación está en crisis... prefiero afirmar (dice) que es la escuela quien se encuentra gravemente enferma y no la educación". Plantea que la educación es el proceso de creación de relaciones posibles, que demandan la referencia constante a las demandas de la heterogeneidad y la diversidad; en cambios, la escolarización (allí el cuerpo) no escapa a los procesos de repetición de relaciones preestablecidas. Guías, manuales, prescripciones de indicadores, seriados de metas y puntualizaciones objetivistas, evaluaciones cartesianas, etc. (todas ellas), estarían en la base de una "educación bancaria" que anula la presencia y el desarrollo de un sujeto creador, activo, no pasivo y no sometido. La escuela, en contravía de la democratización de la vida en sociedad, recuerda Flores d’Arcais citado por Beltrán (2001), estaría anulando el despliegue corporal en una especie de anestesia videocrática.

La profundización del despliegue democrático del cuerpo en la ciudad pasa por la ampliación institucional de los marcos del despliegue corporal no tradicional que exige compromisos de lo público con educaciones e instituciones, con prácticas del cuerpo que riñen con "las buenas costumbres". Lo público en esto a veces debe ir en el límite; hay un cúmulo de prácticas corporales que los sectores conservadores nunca avalarán: la herejía, el sacrilegio, el disenso, el des-orden público, consignas de la salvaguarda funcionarial del cuerpo instituido. La exaltación de la participación y la conciencia crítica individual, las prácticas de vivencia corporal en libertad, configuran denotaciones de un deber ser corporal en la ciudad que demanda, en esto de las prácticas corporales seleccionadas, cultivadas, recreadas y reproducidas, un

\footnotetext{
${ }^{19}$ Las creencias fundantes de la intervención corporal escolar en la escuela, visibles en las primeras décadas de siglo XIX de la mano de los criterios allegados al Nuevo Reino de Granada de la mano de la enculturación pedagógica hispana y posteriormente alemana dejan ver dispositivos que siguen gobernando la atención del cuerpo en el marco de la matriz escolar, entre estos dispositivos: la feminización (histerización), masculinización (heroización), higienización (vigorización) y la militarización (patriotización) (ver Moreno 2005 y 2007)
}

espacio para la aleatoriedad y la espontaneidad del carnaval, prelación (más con la niñez y la juventud) de la lógica del divertimento des-sublimado y de las prácticas corporales expresadas bajo la preeminencia del deseo, de la energía lúdica y de la poética corporal; hasta la ciudad y su funcionariado (allí claro nosotros) tendría que educarse. La funambulización de la calle no es sólo la expresión de una ciudad mendicante como se quiere hacer aparecer, sino que puede ser la expresión de una ciudad que quiere expresar desde otras latitudes ocultas y ocultadas, nuevas formas de aparición de lo corporal.

Para María Cristina Rosa, citada por Soares (2006: 11), se trataría de un cambio en las condiciones de posibilidad del cuerpo institucionalizado, relacionado con "un desvío de algo útil hacia algo inútil", cansados de tanta porra y espectáculo vano con el cuerpo, detentes, clips, instalación, sobre ocupaciones (prácticas y despliegues) poco serias (...); entregarse a prácticas innecesarias y paganas que rayan con lo vulgar y lo popular. Basta mirar por el pistillo de cualquier puerta escolar para ver qué práctica está privilegiando la chiquillada en el patio y la cancha escolar. El juego deportivo y la formación cívica son hegemónicos, pero otras prácticas de bocacalle (traídas de la calle, del extramuro) se vienen tomando el espacio-tiempo escolar. El profesorado y el manual de convivencia han tenido que ceder a las cronémicas y proxémicas de esta nueva presión social hacia el cuerpo. Está por verse si estas fuerzas provenientes de "los usuarios" sacuden la oferta científica y tradicional de la educación física escolar y, en general, de las estéticas corporales recogidas en las disciplinas escolares.

Nuestra opción desde finales del siglo XIX por una "educación física científica" (Crisorio, 2002; Soares, 2006) es una elección que marca nuestro desvío de "las prácticas sin sentido y utilidad" (centradas en las fuerza del deseo y el divertimento), marca la sumisión seria y ejemplar de la educación física con respecto a una "educación bancaria"; alianza que hoy va de la mano de las teorías de la moderna educación eficiente (la del mundo de los indicadores, los evaluadores, las competencias). Se asume que postular el deseable corporal en términos de objetivos, indicadores de logros o metas curriculares basta para garantizar una vivencia corporal formativa en el medio escolar. Los procesos de clasificación, enmarcación y objetivación (naturalizados) no son interrogados y entran en el mundo del sagrado escolar (la escuela en buena medida se debe a este tipo de mitificación). A fuerza de medición puntillosa del actuar del maestro y de la conducta y habilidad del "usuario", 
los pocos (empresarios y prestamistas) intentan salvar el sentido ocioso de la "inversión social escolar"; a una racionalización educativa le corresponde una racionalización corporal. Cambian, desde la política, los sentidos del uso social del espacio y el tiempo; cambian los requerimientos energéticos sobre el cuerpo, cambian los referentes culturales que movilizan al cuerpo frente al saber de sí y el saber de lo otro; cambian las pautas de los intercambios sensibles que definen las estrategias de gobierno de los cuerpos en la escuela o fuera de ella.

El espacio para el florecimiento de las relaciones posibles está lejos de la idea de una escuela que opta por el cuerpo competente, antes que por el ser ${ }^{20}$. La opción científica nos puso al servicio del vigor físico y de la salud, nos alejó del campo de las diversiones, del campo des-sublimado del libre juego, nos acercó al mundo del trabajo, nos alejó de la fiesta, nos acercó al laboratorio, nos alejó de la plaza; nos negó una dimensión de la expresión cotidiana del cuerpo en razón de la protección del vigor físico, las buenas costumbres, la salud física, las ocupaciones útiles y el buen uso de la energía corporall ${ }^{21}$.

Beltrán (2001: 124), citando a Maxine Green, plantea que es muy tentador concentrarse en la instrucción más que en la educación, en las habilidades demandadas por los puestos de trabajo (precario, desigual, injusto y deshumanizado) más que en la felicidad o en la conciencia de sí y en los otros, manteniendo el acuerdo tácito de la preparación para entrar a formar parte de una comunidad donde prima la competitividad (competentes) y donde el norte se sitúa en cómo son las cosas y cómo deben seguir siendo, no en cómo pueden y deben ser para la felicidad y la dignidad de todos y de todas. Aquí, plantea el pedagogo valenciano, cobra sentido, nuevamente, la apelación de Arendt: no es la preocupación 74 por la eficiencia ni por la adaptación al mundo del trabajo la que debe orientar los procesos formativos; diríamos acá, lo que deba orientar la recontextualización y la propia contextualización de las prácticas corporales; debemos prestar atención a nuevos compromisos con el cuerpo escolar. Bajo la hegemonía y la subyugación del compromiso fisiológico ${ }^{22}$, las educaciones del cuer-

\footnotetext{
${ }^{20}$ Parea ampliar el debate entre la opción contemporánea de la escuela por el ser competente, antes que por el ser, véase el interesante texto de Ricardo Crisorio en Revista de Educación Física y Deporte, vol. 2, 2006. Medellín.

${ }^{21}$ Para ampliar el debate entre divertimiento y competencia física (vigor, salud), véase Ainsestein A. (2006). Cuerpo y cultura: prácticas corporales y diversidad el texto de Carmen Lucia Soares "Prácticas corporales: historias de lo diverso y lo homogéneo".

22 Para dimensionar la preeminencia del compromiso fisiológico en las prácticas corporales escolares, así como su sustentación pedagógica, véase el trabajo "La importancia del compromiso motor y el compromiso fisiológi-
}

po no responden, en el medio escolar, a las solicitudes axiológicas, éticas, políticas y estéticas de un cuerpo que reclama la ciudad.

Desde una perspectiva conservadora, estaría sobredimensionándose la norma de la escuela "lineal eficientista" en favor de la enseñanza de los contenidos, y el logro de las competencias preestablecidas en función de los conocimientos y las habilidades "productivas" a favor de los mejor dotados y adaptados, en favor de la disciplina, el buen comportamiento y la homogeneidad; en detrimento de los ruidos, de la des-atención, el des-orden y la di-versidad, en detrimento de los intereses de los más que incluye a los no (hiperactivos, mujeres, enfermos, des-atentos, disminuidos físicos, necios, minorías, discapacitados, críticos, etc.). De cara a la comprensión de nuestra intervención pedagógica del cuerpo escolarizado, hoy cobra relevancia la lectura de los intercambios estéticos que se sugieren en la escuela, con el cuerpo, en la retórica tradicional de la educación corporal. El Estado, lo jurídico, lo escolar, lo deportivo y lo médico, reflejan dispositivos de control, gestión y con-formación de los cuerpos en el contexto de la escuela que deben ser reflexionados; en la trama de los intercambios complejos, allí visibles, entre el poder de las matrices sociales (estatal, escolar, médica, familiar, medial) se dibuja una trama social desde donde se constituye la intervención con-formadora del futuro ciudadano.

\section{Desescolarizar la escuela para el cuerpo}

Las prácticas corporales curricularizadas y homogéneas, planificadas desde fuera por los expertos contratados y plasmados en los textos guías o facilitados en los cursillos profesorales ya no representa una fuente tan importante del conocimiento profesoral. Hoy desde la calle, la televisión, los turismos privados o complementarios, y los videojuegos se promueven formas alternas de divertimento y ejercitación corporal. Ante la chiquillada, la oferta del profesor tiende a quedar out, a sonar dinosáurica; en general, niños y jóvenes murmuran por lo bajo sobre lo arcaico de la escuela y de su desfase con el espacio-tiempo, el emocionar y los códigos cultura-

\footnotetext{
co durante las clases de educación física" de David Martínez Gómez, María Victoria Sampedro y Óscar L. Veiga Núnez en la Revista Iberoamericana de Educación, 42(2) de 2007 (http://www.rieoei.org/1631.htm), o los planteamientos de A. Sierra (2003), en Actividad física y salud en primaria: el compromiso fisiológico en la clase de educación física, Sevilla. Wanceullen y los trabajos pioneros sobre el asunto en Eduardo Generello (1996), "Una aproximación al estudio del compromiso fisiológico en la educación física escolar y el deporte educativo", en CSD, 10, 53-88. Madrid.
} 
les jugados de la ciudad. Otros temas, alrededor de lo formal y lo informal de las prácticas corporales deben problematizarnos; las educaciones corporales deben pensar que es necesario profundizar en una atención corporal pública, que en contravía de los vestigios biologistas (soporte racista), vea las diferencias entre los escolarizados como salvables o equilibrables valiéndonos de la inversión pública como energía reguladora de un acceso equitativo a las prácticas corporales de ciudad. A escasos metros, en una misma localidad, asisten niños, jóvenes, adultos y viejos a prácticas de educación corporal profundamente inequitativas en una corporalización escolar o recreacional para la desigualdad y la exclusión.

En la escuela, la masificación (racionalización educativa) se muestra como un medio proclive al desarrollo de estrategias pedagógicas o clínicas deplorables para la dignidad corporal: la indisciplina (reacción consecuente con la alta densidad escolar exigida por el empresalismo educativo) es "confundida" con estigmas de "hiperactivismo enfermizo" y "agresividades psicóticas". Las intervenciones corporales recurren al uniformismo, el aquietamiento y a una cuadriculación conductual que garantice ordenamientos corporales que recuerdan épocas oscuras del disciplinamiento corporal. La ritalina, el ácido metil fenidato, el encierro, la exclusión de actividad como castigo o el premio a "los juiciosos", a "los quietos", a los "acríticos", a los "sapos", aparecen como opciones de regulación corporal que se camuflan en operaciones corporales del cotidiano escolar.

En la ciudad, en el marco de las atenciones y las dispensaciones corporales con-formadoras, hemos acumulado un saber hacer y un poder hacer para agredir los cuerpos (menores, niñas, mujeres, indigentes, homosexuales, negros, trabajadores informales, prostitutas, especiales, etc.). Estas actitudes demandan un profundo estudio y una investigación social insertos en los procesos de formación del profesorado y, en general, de cara a la reconfiguración de los procesos de educación corporal que emprenda la ciudad en los diferentes escenarios sociales de atención a lo corporal. Autoflagelación, ayuno, acoso, rumbas extremas con patrocinio público, ex- plotación infantil, prostitución precoz, tortura, ocultamiento, desaparición, encierros, castigos, exclusiones... el listado es amplio.

La ciudad, en su recato egoísta, desprecia a los que escapan ${ }^{23}$. Ignoramos sus creencias y sus prácticas corporales. Se les recibe, como si carecieran de cultura, imponiéndoles la cultura corporal hegemónica. Se les trata como menores, o incompletos e inmaduros; la indigenidad o la ruralidad son vistas como estadios de carencia cultural. En el marco de la manipulación laboral y la supervivencia familiar, el cuerpo infantil está sometido a prácticas de con-formación laboral precoz, que coartan el libre desarrollo. El pleno desarrollo corporal es una preocupación central de la educación que puede orientar los procesos de regulación ciudadana sobre la utilización temprana de los niños en trabajos malformantes (...). Las condiciones de la maternidad precoz, del embarazo escolar, del aborto, demandan una concepción del cuerpo en el funcionariado público (incluido el profesorado) y condiciones para la investigación y la inversión en educación corporal en el contexto del bienestar social en la ciudad. Revisar, confrontar y proyectar una cultura del cuerpo que favorezca procesos de atención y comprensión ciudadana con relación a las pautas y cuidado corporal en ciudad.

En los desplazamientos, en las atenciones e intervenciones de lo corporal, un sinnúmero de prácticas de sumisión, de reacomodamiento, de subsistencia y de resistencia corporal que se pueden leer de cara a percibir el cuerpo que nos asignaron; identificar el cuerpo que existe y padece, que goza y que se planta (incluso ante nosotros) de cara al futuro de la ciudad. Nos resta abrir sentido. Es posible que nuestras escuelas puedan ser de otra manera y el cuerpo pueda desplegarse dignamente; eso implica cambios profundos en la dinámica de la escolarización (desescolarizar la escuela para el cuerpo), pero sobre todo exige procesos profundos de redefinición de nuestro actuar desde lo que creemos y decimos saber y saber hacer. La historia y la experiencia en el cotidiano escolar hablan mucho de lo posible con el cuerpo. $(\mathbb{D}$

\footnotetext{
${ }^{23}$ En 2005 se presentaron más de 131.000 casos de desplazamiento forzado. Acnur afirma que el número de personas desplazadas internamente en Colombia supera los dos millones. Según Unicef, más de la mitad son niñas y niños (1.100.000).
} 


\section{Referencias}

Adorno, T. (1993) Consignas. Buenos Aires. Amorrourto Editores.

Barbero, J. I. (1993). Las redes de la cultura física. Aproximación genealógica al saber médico en educación física. José Ignacio Barbero González (Ed.). Investigación alternativa en Educación física. En II Encuentro Unisport sobre Sociología deportiva Málaga: Unisport (pp. 7-30).

Beltrán, Ll. F. (2006). Hannah Arendt y John Dewey: sobre lo público y la educación. Institut universitari d'estudis de la dona de la Universitat de Valéncia [home page] consultado el día 14 de marzo de 2007 en el sitio Web: http://www.uv.es/iued/actividades/articulos/beltran.htm

Bracht, V. (2002). Identidad y crisis de la educación física: un enfoque epistemológico. R. Crisorio y V. Bracht (Coordinadores): La educación física en Argentina y Brasil. Identidad, desafíos y perspectivas. La Plata, Argentina: Ediciones Al Margen.

Calvo, M. C. (1994). Del mapa escolar al territorio educativo $\dot{i}$ Crisis de la educación o crisis de la escuela? En J. Osorio y L. Weistein (ed): El corazón del arco iris: lecturas sobre nuevos paradigmas en educación y desarrollo. Santiago de Chile: Consejo de Educación de Adultos de América Latina, CEAAL.

Calvo, M. C. (1985). Currículum oculto y educación informal. Revista Signos, AGECH, 1.

Carr, W. y Kemmis, S. (1988). Teoría crítica de la enseñanza. Madrid: Martínez Roca.

Crisorio R. (2006). La diferencia entre ser y ser competente. Revista de educación física y deporte, 25(2), 95-106. Medellín:Universidad de Antioquia.

Crisorio, R, (2003). Educación física e identidad: conocimiento, saber, verdad. En R. Crisorio y V. Brath (coordinadores). La educación física en Argentina y en Brasil. Identidad, desafíos y perspectivas. La Plata, Argentina: Ediciones Al Margen.

Deleuze, G. (1998). El auge de lo social. En J. Donzelot. La policía de las familias. Valencia: Pre-textos.

Díaz, M. (2001). Del discurso pedagógico: problemas críticos. Bogota: Cooperativa Editorial Magisterio.

García, C., Franco, S., García, F., Vásquez C. y Urrego, L. (2002). Discursos de la educación física del siglo XIX en Medellín. Medellín: Instituto Universitario de Educación Física de la Universidad de Antioquia.

García, C., García, F., Cañas, E., Villegas, D., Giraldo, A., Peralta, E. y Páez, J. (2000). Recuperación documental de los discursos acerca de la educación física del siglo XIX registrado en Medellín, Medellín: Instituto Universitario de Educación Física de la Universidad de Antioquia.

Foucault, M. (1994). Hermenéutica del sujeto. Madrid: La Piqueta.

Foucault, M. (2002). Vigilar y castigar. Nacimiento de la prisión. Buenos Aires: Siglo XXI Editores.

Foucault, M. (1999). Estrategias de poder. Barcelona: Paidós.

Gil, F., Rico, L., Fernández y Cano, A. (2002). Concepciones y creencias del profesor de secundaria sobre evaluación de Matemáticas. Revista de investigación educativa, 20 (1), 47-75.
Gyroux, H. (2003). La inocencia robada: Juventud, multinacionales $y$ política cultural. Pablo Manzano (trad.). Madrid: Morata.

Herrera, X. y Buitrago, Nelly. (2005). Cuerpo y silencio en la escuela de comienzos del siglo XX en Colombia. Revista Pedagogía y Saberes, 21. Bogotá: Universidad Pedagógica Nacional.

Herrera, X. y Buitrago, Nelly. (2005). Juego y escuela a comienzos del siglo XX. Ponencia presentada al II Congreso de Historia de la Educación Física. Bogotá, Colombia.

Herrera, X. y Buitrago, Nelly. (1999). Las prácticas corporales y la educación física en la escuela primaria en Colombia entre 1870 y 1913: Resultados de la investigación. Revista Lúdica Pedagógica, 4. Bogotá: Universidad Pedagógica nacional.

López R. J. I. (1999). Conocimiento docente y práctica educativa. Málaga: Ediciones Aljibe.

McLaren, P. (1994). Pedagogía crítica, resistencia cultural y la producción de deseo. Buenos Aires: Instituto de Estudios y Acción Social-Aique Grupo Editor.

Moreno, W. (2003). La relación creer-saber-poder en la disposición político-cultural del profesorado de educación física, tesina inédita. Valencia: Universidad de Valencia.

Moreno W. (2007, mayo) Los dispositivos escolares de la sujetación corporal. Conferencia presentada en el VII Congreso Argentino y II Congreso Latinoamericano de Educación Física y Ciencias. Mar del Plata, Argentina.

Milstein D. y Mendes H. (1999). La escuela en el cuerpo. Estudios sobre el orden escolar y la construcción social de los alumnos en escuelas primarias. Buenos Aires: Miño y Dávila Editores

Pedraza G. S. (2004). El régimen biopolítico en América Latina, Cuerpo y pensamiento social. Iberoamericana, nueva época, 4 (15), 7-19.

Sáenz, J., Saldarriaga, Ó., y Ospina, A. (1997). Mirar la infancia: pedagogía, moral y modernidad en Colombia, 1903-1946, tomos 1 y 2. Medellín: Editorial Universidad de Antioquia-ColcienciasEdiciones Foro Nacional por Colombia, Ediciones Unidas.

Schön, D. (1992). La formación de profesionales reflexivos. Barcelona: Paidós

Soares, C, L. (2006). Prácticas corporales: historias de lo diverso y lo homogéneo. En A. Ainsestein (ed). Cuerpo y cultura: prácticas corporales $y$ diversidad. Buenos Aires: Edita Libros del Rojas.

Taborda, M. (2002). Las prácticas pedagógicas de la educación física en los tiempos y espacios escolares: ¿la corporalidad como término ausente? En R. Crisorio y V. Bracht (Coords.). La Educación Física en Argentina y Brasil. Identidad, desafíos y perspectivas. La Plata, Argentina: Ediciones Al Margen.

Varela, J. (1997). Nacimiento de la mujer burguesa. Madrid: La Piqueta

Zuluaga, O. L. (1999a). La educación pública en Colombia 1845-1875. Libertad de enseñanza y adopción de Pestalozzi en Bogotá, Bogotá: IDEP-Universidad de Antioquia.

Zuluaga, O. L. (1999b). Pedagogía e Historia. Medellín: AnthroposSiglo del Hombre Editores-Universidad de Antioquia.

Zavaleta, C. (2005). El paisaje en la relación cuerpo ciudad. Memorias del Foro sobre urbanismo y paisaje. Vitoria. 